\title{
Spread of Infectious Complications of Odontogenic Abscess Detected by Technetium- 99m-HMPAO-Labeled WBC Scan of Occult Sepsis in the Intensive Care Unit
}

\author{
Chai-Hung Kao and Shyn-Jen Wang \\ Department of Nuclear Medicine, Taichung Veterans General Hospital, Taichung, Taiwan, Republic of China
}

\begin{abstract}
We report a rare case of odontogenic abscess, detected while the patient was in the intensive care unit (ICU), which resulted in sepsis and the patient's death due to mediastinitis, skull osteomyelitis, and deep neck cellulitis. The detection of infectious focus in occult sepsis in ICUs is usually difficult because many diagnostic procedures cannot be conveniently performed. The use of ${ }^{92 m}$ Tc-hexamethylpropyleneamineoxime-labeled white blood cells scan allowed accurate diagnosis and appropriate surgical drainage.
\end{abstract}

J Nucl Med 1992; 33:254-255

$\mathrm{D}$ espite the use of antibiotics, cases of odontogenic infections still occur when there is an initial delay in treatment, an underlying systemic disease, or because of the nature of the responsible microorganism, these inspections may result in rare and life-threatening complications $(1,2)$. Therefore, early diagnosis and precise evaluation of the extent of the complications are very important. An easily available imaging technique that could accurately demonstrate the sites of infection in an ICU patient with occult sepsis would be of great value. Our experience encouraged the use of a ${ }^{99 m}$ Tc-HMPAO-WBC scan in such a case.

\section{CASE REPORT}

A 62-yr-old man suffered from a toothache for two days with swelling of the right parotid region and erythmous change of the anterior neck. Physical examination showed the swelling of the right temporal, parotid, sublingual, submental, submandibular, anterior neck, and supraclavicle regions. Pericoronitis of the lower right third molar with pus discharge was seen. Abnormal breath sounds of dullness over the right upper lung field also were noted.

Received Jan. 25, 1991; revision accepted Sept. 4, 1991.

For reprints contact: Chia-Hung Kao, MD, Department of Nuclear Medicine, Taichung Veterans General Hospital, 160 Taichung Harbor Road, Section 3, Taichung 40705, Taiwan, Republic of China.
The patient developed dyspnea and hypotension, and was then admitted to the ICU with sepsis. A chest $x$-ray showed slight enlargement of the superior mediastinum. Technetium- $99 \mathrm{~m}$ HMPAO-WBCs were prepared $(3,4)$, and $4 \mathrm{hr}$ after intravenous injection of $260 \mathrm{MBq}{ }^{99 \mathrm{~m}} \mathrm{Tc}-\mathrm{HMPAO}-\mathrm{WBC}$ the image demonstrated significant WBC accumulation in the right temporal, parotid, submandibular regions, neck, and superior mediastinum (Fig. 1). Incision, drainage and debridement of the abscess was done with the guidance of scintigraphic findings. Bacterial culture showed growth of Staphylococcus aureus and Pseudomonas aeruginosa. In spite of antibiotic therapy, an acute respiratory distress syndrome developed and the patient died.

\section{DISCUSSION}

On rare occasions odontogenic infections result in lifethreatening complications: airway obstruction, necrotizing fasciitis of the neck, rapid spread to adjacent areas such as orbit, cranium, mediastinum and thorax, as well as hematogenous dissemination $(5,6)$. Early diagnosis of complications, prompt surgical treatment, and judicious selection of appropriate antibiotics are very important $(6,7)$.

CT scanning has been advocated in the management of deep head and neck infections ( 8 ) and mediastinitis (9, $10)$, but its benefits must be weighed against the time necessary to schedule and obtain the scan (8). Gallium67-citrate has been advocated for the detection of an infectious lesion or abscess formation, but the potential requirement for delayed images and difficulty in interpretation (11) are serious drawbacks. Indium-111-labeledWBC scans are more accurate and provide data in a shorter time than ${ }^{67} \mathrm{Ga}$ for abscess localization $(12-14)$. However, "I'In is not commonly available and is expensive, which therefore limits its application. Technetium- $99 \mathrm{~m}$ is a more desirable radionuclide since it is readily available and its photon energy is better suited for imaging with a mobile gamma camera. Because ${ }^{99 m}$ Tc-HMPAO is lipophilic, the agent can label WBCs similar to "'In complexes, and good results have been reported (3).

Our experience suggests that the use of ${ }^{99 \mathrm{~m}} \mathrm{Tc}$-HMPAOWBC scan should be encouraged in the ICU. 

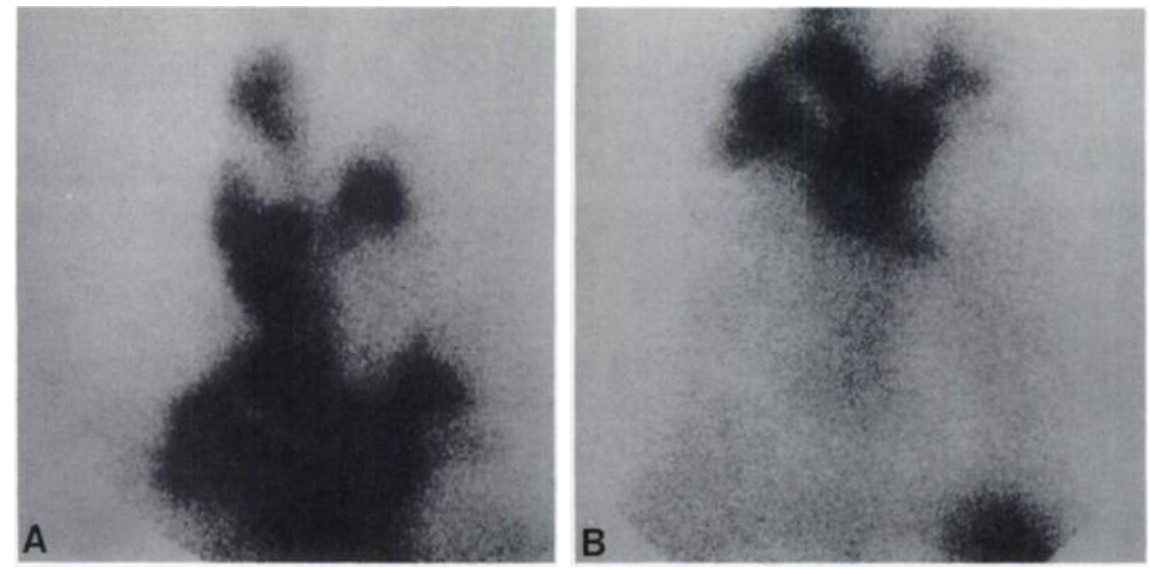

FGURE 1. Tectnetium-99m-HMPAOlabeled WBC scan. (A) Anterior view of the head and neck showed intense labeled WBC accumulation in the right temporal, parotid, submental, submandibular regions and neck and (B) anterior view of the neck and chest revealed intense labeled WBC accumulation in the neck and superior mediastinum.

\section{REFERENCES}

1. Bounds GA. Suphrenic and mediastinal abscess formation: a complication of Ludwig's angina. Br J Oral Max Surg 1985;23:313-321.

2. Zaputowycz $O$, Williams FA, Arthur A. Bilateral lung abscess with masticator space infection. Oral Surg 1986;61:327-329.

3. Peters AM, Danpure HG, Osman S, et al. Clinical experience with ${ }^{99 m} \mathrm{Tc}$ hexamethylpropyleneamine oxime for labelling leukocytes and imaging inflammation. Lancet 1986;25:946-949.

4. Uno K, Imazeki K, Yoshikawa K, Arimizu N. Clinical use of technetium99m-HMPAO-labeled leukocyte for inflammatory imaging. J NuCl Med 1987;28:648.

5. Megran DW, Scheifele DW, Chow AW. Odontogenic infections. Pediatr Infect Dis J 1984;3:257-265.

6. Dierks EJ, Meyerhoff WL, Schultz B. Finn R. Fulminant infections of odontogenic origin. Laryngoscope 1987;97:271-274.

7. Wills PI, Vernon RP, Smith F. Complications of space infections of the head and neck. Layrngoscope 1981;91:1129-1136.
8. Spankus EM, Flint PW, Smith RJH. Craniocervical necrotizing fascitis. Otolaryngol Head Neck Surg 1984;92:261-265.

9. Browdie DA, Bernstein RW, Agnew R, Damle A, Fischer M, Balz J. Diagnosis of poststernotomy infection: comparison of three means of assessment. Ann Thorac Surg 1991;51:290-292.

10. Musgrove BT, Malden NJ. Mediastinitis and pericarditis caused by dental infection. Br J Oral Max Surg 1989;27:423-428.

11. Kipper MS, Williams RJ. Indium-111 white blood cell imaging. Clin $\mathrm{NuCl}$ Med 1983;8:449-455.

12. Sfakianakis GN, Al-Sheikh W, Heal A, et al. Comparison of scintigraphy with In-111-leukocytes and $\mathrm{Ga}-67$ in the diagnosis of occult sepsis. $J$ NuCl Med 1982;23:618-626.

13. Thakur ML, Coleman RE, Welch MS. Indium-111-labeled leukocytes for the localization of abscesses: preparation analysis, tissue distribution and comparison with gallium-67 citrate in dogs. J Lab Clin Med 1977;89:217228.

14. Froelich JW, Swanson D. Imaging of inflammatory processes with labeled cells. Semin Nucl Med 1984;14:128-140. 